\title{
Maiwei Yangfei decoction prevents bleomycin-induced pulmonary fibrosis in mice
}

\author{
YONG XU $^{1 *}$, WENPAN PENG $^{1 *}$, DI HAN $^{1}$, FANCHAO FENG $^{1,2}$, \\ ZHICHAO WANG ${ }^{1}$, CHENG GU ${ }^{1}$, XIANMEI ZHOU ${ }^{1,2}$ and QI WU ${ }^{3}$ \\ ${ }^{1}$ Department of Respiratory and Critical Medicine, Affiliated Hospital of Nanjing University of Chinese Medicine; \\ ${ }^{2}$ Department of Respiratory and Critical Medicine, Jiangsu Province Hospital of Chinese Medicine, Nanjing, \\ Jiangsu 210029; ${ }^{3}$ Department of Physiology, Xuzhou Medical University, Xuzhou, Jiangsu 221009, P.R. China
}

Received March 22, 2021; Accepted July 28, 2021

DOI: $10.3892 /$ etm.2021.10741

\begin{abstract}
Maiwei Yangfei (MWYF) is a compound Chinese herb that is safe and effective in the clinical setting in patients with pulmonary fibrosis (PF). The aim of the present study was to assess the role of a (MWYF) decoction in a bleomycin (BLM)-induced PF mouse model and to investigate the underlying functional mechanism. Chemical components within the MWYF decoction were analysed using liquid chromatography-mass spectrometry. A total of 50 C57BL/6 mice were randomly assigned to one of the following five groups with 10 mice per group: Control, model, low dose MWYF (20 g/kg), medium dose MWYF (40 g/kg) and high dose MWYF (60 g/kg). A mouse PF model was established by the tracheal instillation of BLM $(5 \mathrm{mg} / \mathrm{kg})$ prior to MWYF treatment, except for mice in the control group. After 21 days of treatment with MWYF, the mice were sacrificed and the body weights were recorded. In addition, pulmonary tissues and bronchial alveolar lavage fluid were collected. TNF- $\alpha$, IL-6, IL-17, hydroxyproline, pyridinoline and collagen I levels were determined using ELISA. Vimentin, $\alpha$-smooth muscle actin ( $\alpha$-SMA), fibronectin, TGF- $\beta 1$, Smad3, TNF- $\alpha$, IL-6, IL-17, collagen I and collagen III were determined using western blotting. Vimentin and $\alpha$-SMA levels were also determined using immunofluorescence analysis. Collagens I and III were detected using immunohistochemical analysis and TGF- $\beta 1$ and Smad3 levels were determined using reverse transcription-quantitative PCR. Following treatment with MWYF decoction, the body weight of the mice in the PF
\end{abstract}

Correspondence to: Professor Xianmei Zhou, Department of Respiratory and Critical Medicine, Affiliated Hospital of Nanjing University of Chinese Medicine, 155 Hanzhong Road, Nanjing, Jiangsu 210029, P.R. China

E-mail: zhouxianmeijs@aliyun.com

${ }^{*}$ Contributed equally

Key words: Maiwei Yangfei decoction, pulmonary fibrosis, bleomycin, collagen group increased, the degree of pulmonary alveolitis and PF was reduced, collagen levels were reduced and the expression levels of $\alpha$-SMA, vimentin and fibronectin were decreased. Although both protein and mRNA expression levels of TGF- $\beta 1$ and Smad3 were reduced, they remained higher than those observed in the control group. To conclude, MWYF decoction delayed the development of BLM-induced PF in mice, where the functional mechanism was likely associated with the TGF- $\beta 1 / \mathrm{Smad} 3$ signalling pathway.

\section{Introduction}

Pulmonary fibrosis (PF) is a chronic, progressive and potentially lethal pulmonary interstitial disease that primarily occur in middle-aged and elderly individuals $(1,2)$. This disease is characterized by an unusual interstitial pneumonitis, where fibrosis and honeycomb-like lesions can be observed at the sub-pleura and basal pleura $(3,4)$. In addition, deposition of collagen and extracellular matrix (ECM) occur at the peripheral PF locus, which ultimately results in structural changes in the pulmonary tissues, loss of pulmonary ventilation, pulmonary diffusion and even mortality $(3,4)$. PF is a pulmonary disease, with a median survival time of only 2-4 years in patients who do not receive lung transplants, making it a severe lung disease (5). In particular, the incidence of PF continues to rise with an increased aging population worldwide (6). However, the underlying pathogenic mechanism of PF remain poorly understood (7).

It has been previously hypothesized that PF is closely associated with alterations in alveolar epithelial cells and pulmonary fibroblasts (6). In PF, the initiating factor is typically alveolar epithelial cell injury (8). After the epithelial cells are aberrantly activated due to external damage and stimulation, they secrete large quantities of inflammatory factors, including IL-6, IL-17 and TGF- $\beta 1(9,10)$. This induces the conversion of epithelial cells into fibroblast, causes the chemotaxis of mononuclear cells in the circulatory system into the pulmonary space, transformation of pulmonary fibroblasts into myofibroblasts and the secretion and deposition of large amounts of ECM into the pulmonary tissues, leading to morphological and structural changes in the pulmonary tissues (11-13). 
At present, a therapeutic strategy that is fully effective for the treatment of PF remain unavailable. The clinically applied pirfenidone and nintedanib can only delay the deterioration of lung function in patients with slight-to-moderate PF $(14,15)$. Additionally, $\mathrm{N}$-acetylcysteine can only improve the survival rate in patients with the recombinant toll interacting protein TT genotype (16). Over the past decade, with increased interest in traditional Chinese medicine (TCM) and symptom-based and disease-based approaches, a growing number of clinical trials and studies have emerged regarding the treatment of PF using extracts of Chinese medicine, highlighting the potentially novel methods and for the treatment of PF (17-21). Therefore, it may prove to be beneficial to explore the applicability of Chinese medicine to fully exploit its unique advantages, whilst at the same time to characterize the bioactive medicinal compounds contained within the TCM for the treatment of PF.

In the present study, a single-use bleomycin (BLM) instillation method was used to establish a PF mouse model, which was subsequently treated using MWYF by intragastric administration. In the PF mice, the role of MWYF decoction was investigated, in addition to the possible mechanism of action.

\section{Materials and methods}

Reagents and instruments. The MWYF decoction was obtained from Jiangsu Province Hospital of Chinese Medicine. BLM was supplied by TCI (cat. no. B3972-10MG, Shanghai, China). Hydroxyproline (HYP; cat. no. F10614), pyridinoline (PYD; cat. no. F11442), collagen I (F5760; all from Shanghai Westang Bio-Tech Co., Ltd.), TNF- $\alpha$ (cat. no. 70-EK282/3-96), IL-6 (cat. no. 70-EK206/3-96) and IL-7 [cat. no. 70-EK207/2-96; all from MULTISCIENCES (LIANKE) BIOTECH, CO., LTD] were ELISA test kits. $\alpha$-Smooth muscle actin ( $\alpha$-SMA; cat. no. 14395-1-AP), vimentin (cat. no. 10366-1-AP 14395-1-AP), fibronectin (cat.no.15613-1-AP), collagen I (cat. no. 14695-1-AP), collagen III (cat. no. 22734-1-AP), TNF- $\alpha$ (cat. no. 17590-1-AP), IL-6 (cat. no. 21865-1-AP), IL-17 (cat. no. 13082-1-AP), TGF- $\beta 1$ (cat. no. 21898-1-AP), Smad3 (cat. no. 25494-1-AP) and $\beta$-actin (cat. no. 20536-1-AP) antibodies were purchased from Wuhan Sanying.

Preparation of MWYF decoctionand qualitycontrol standards. The MWYF decoction included 15 g Codonopsis pilosula, 15 g Michaelmas daisy, $10 \mathrm{~g}$ Radix ophiopogonis, $10 \mathrm{~g}$ Schisandra chinensis, $10 \mathrm{~g}$ perilla fruit, $10 \mathrm{~g}$ Pinellia ternate, $10 \mathrm{~g}$ Scutellaria baicalensis, $10 \mathrm{~g}$ Angelica sinensis, $10 \mathrm{~g}$ tangerine peel, $6 \mathrm{~g}$ fried Chinese ephedra, $3 \mathrm{~g}$ Asarum sieboldi and $3 \mathrm{~g}$ fried glycyrrhiza. The raw drug material was identified and authenticated by Professor Zhu Yufeng (Department of Pharmacy, Jiangsu Province Chinese Medicine Hospital, Jiangsu, China). A total of 5 doses of MWYF raw drug material was immersed in $31 \mathrm{ddH}_{2} \mathrm{O}$ at $20^{\circ} \mathrm{C}$ for $30 \mathrm{~min}$. The mixture of water and raw drug material was then boiled to $120^{\circ} \mathrm{C}$ for $30 \mathrm{~min}$ and a decoction was collected. This procedure was repeated twice and the decoctions were pooled together. The 5 doses of decoction were centrifuged at $500 \mathrm{x} \mathrm{g}$ before the supernatant was collected, filtered, concentrated and freeze-dried to obtain a freeze-dried powder, which was used to prepare different concentrations of MWYF.
The characteristic components in the MWYF decoction were qualitatively analysed using liquid chromatography-mass spectrometry (LC-MS). Briefly, $50 \mathrm{mg}$ freeze-dried samples were extracted using $800 \mu 180 \%$ methanol and $10 \mu \mathrm{l}$ internal standard $(2.8 \mathrm{mg} / \mathrm{ml}$, DL-o-chlorophenylalanine) and then vortexed for $30 \mathrm{sec}$. Next, the samples were ultrasonicated for $30 \mathrm{~min}$ at $40 \mathrm{kHz}$ at $50^{\circ} \mathrm{C}$ and all owed to stand for $1 \mathrm{~h}$ at $20^{\circ} \mathrm{C}$. The samples were centrifuged $1,800 \mathrm{x} \mathrm{g}$ and $4^{\circ} \mathrm{C}$ for $15 \mathrm{~min}$. The supernatant was collected in small vials and then used for evaluation by LC-MS (UltiMate ${ }^{\mathrm{TM}}$ 3000, Q Exactive ${ }^{\mathrm{TM}}$; Thermo $^{\text {Th }}$ Fisher Scientific, Inc.). LC-MS was performed using a C18 chromatographic column (Hypersil GOLD C18; 100x2.1 mm, $1.9 \mu \mathrm{m}$; Thermo Fisher Scientific, Inc.). Chromatographic isolation was performed at a column temperature of $40^{\circ} \mathrm{C}$ with a $0.3 \mathrm{ml} / \mathrm{min}$ flow rate. The composition of the mobile phase A was water $+5 \%$ acetonitrile and $0.1 \%$ formic acid, while mobile phase $\mathrm{B}$ was composed of acetonitrile $+0.1 \%$ formic acid. The injection volume was $10 \mu \mathrm{l}$. The temperature of the autosampler was $4^{\circ} \mathrm{C}$.

Method for model construction. A single dose intratracheal instillation of BLM was used to construct the PF mouse model. The mice were first anesthetized by an intraperitoneal injection of $3 \%$ sodium pentobarbital $(40 \mathrm{mg} / \mathrm{kg})$ and fixed on the operating table $(22,23)$. Along the neck, the skin was cut open lengthways and the trachea was passively exposed. A blunt no. 7 lumbar spinal needle was inserted slowly into the trachea along the root of the tongue. The needle was then inserted with the depth of $2.8-\mathrm{cm}$ and $5 \mathrm{mg} / \mathrm{kg}$ BLM was slowly instilled (24). The control group was treated in a manner similar to that in the treatment group, with physiological saline instilled instead of BLM. To ensure even distribution of BLM into the lung tissues, the mice were moved back and forth and upside down.

Test animals and grouping. A total of $50 \mathrm{SPF}$ grade C57BL/6 male mice (weight, 20-25 g) were supplied by the Qinglongshan Animal Centre [Jiangning, Nanjing; licence no. SCXK (Su) 2017-0001; certification no. 201903602]. The mice were reared at the SPF grade test animal centre at the Nanjing University of Traditional Chinese Medicine at $22^{\circ} \mathrm{C}$ and $46 \%$ relative humidity, with a 12-h light/dark cycle. The mice were provided with ad libitum access to food and water and were allowed to acclimatise to the new environment for 1 week prior to experimentation. All experimental studies followed the Guide for the Care and Use of Laboratory Animals (25). The present study was approved by the Ethics Commission for Animal Tests of the Nanjing University of Traditional Chinese Medicine (Nanjing, China). A total of 50 mice were randomly assigned into five groups (10 mice in each group). For the control group, saline was administered through oral gavage. After the PF model was successfully established, mice in the model group were administered with saline through oral gavage. The treatment groups also received BLM to establish the model, but then subsequently received 20, 40 or $60 \mathrm{~g} / \mathrm{kg} /$ day MWYF soup by gavage from days 1 to 21 . Body weight was measured every 2 days. The unit used for the MWYF dosage is termed the total raw material. Fur color, behaviour and other vital signs were observed every day. A total of 21 days after continuous administration of MWYF, the mice were intraperitoneally injected 
with $3 \%$ sodium pentobarbital $(150 \mathrm{mg} / \mathrm{kg}$ ) for euthanasia (23). Lung tissues and bronchoalveolar lavage fluid (BALF) were then collected. For each mouse, the lower lobe of the right lung was collected and fixed in $4 \%$ paraformaldehyde $\left(4^{\circ} \mathrm{C} ; 24 \mathrm{~h}\right)$. The remaining lung tissues were maintained in $2 \mathrm{ml}$ tubes and flash-frozen in liquid nitrogen. The samples were then stored at $-80^{\circ} \mathrm{C}$ until required for further analysis.

Pulmonary alveolitis and PF scoring. Lung tissues were fixed in $4 \%$ polyoxymethylene $\left(4^{\circ} \mathrm{C}\right)$ for $24 \mathrm{~h}$. The tissues were embedded in paraffin and cut into $4-\mu \mathrm{m}$ thick sections. The slices were then subjected to H\&E and Masson staining. The levels of alveolar inflammation were scored using Szapiel's method (26). The levels of PF were scored using Ashcroft's method (27).

Collagen I, HYP, PYD and inflammatory cytokines in pulmonary tissues and BALF. The optical density (OD) value was measured after ELISA was performed according to the manufacturer's protocols, before the final content of HYP and PYD was calculated using a standard curve.

TNF- $\alpha$, IL- 6 and IL-17 levels in BALF were determined using ELISA, according to the manufacturer's protocol. The colour was developed at room temperature, the OD was recorded and TNF- $\alpha$, IL- 6 and IL-17 levels in the BALF were calculated using a standard curve.

Immunohistochemical determination of collagen I and collagen III. Lung tissue sections $(5 \mu \mathrm{m})$ were deparaffinized with xylene and ethanol and washed with PBS. A few drops of $3 \% \mathrm{H}_{2} \mathrm{O}_{2}$ were added to block endogenous peroxidase activity at $25^{\circ} \mathrm{C}$ for $25 \mathrm{~min}$ in the dark. Antigen retrieval was performed by boiling in citrate buffer solution at $95^{\circ} \mathrm{C}$ for $20 \mathrm{~min}$. The tissues were then blocked with 3\% BSA (cat. no. R22294; ShangHai YuanYe Biotechnology Co., Ltd.) at $25^{\circ} \mathrm{C}$ for $30 \mathrm{~min}$ Collagen I and collagen III antibodies were added to the samples at $4^{\circ} \mathrm{C}$ for $12 \mathrm{~h}$, which were placed in a wet box. After overnight incubation, the secondary antibody (Biotin-conjugated Affinipure Goat Anti-Rabbit; 1:500; cat. no. SA00004-2; ProteinTech Group, Inc.) was applied at $25^{\circ} \mathrm{C}$ for $50 \mathrm{~min}$, and the signal was revealed using 3,3'-diaminobenzidine reagent (cat. no. 8059S; Cell Signalling Technology, Inc.) followed by sealing of the sections with neutral resin. The expression of collagen I and collagen III were observed under a light microscope (XSP-C204; Chongqing Chongguang Industrial Co., Ltd.) at a magnification of x200. Results were quantified using ImageJ software (v.1.52; National Institutes of Health).

Determination of vimentin and $\alpha-S M A$ expression using immunofluorescence analysis. Lung tissue slices $(5 \mu \mathrm{m})$ were incubated in citrate buffer $(0.01 \mathrm{~mol} / \mathrm{l}$; $\mathrm{pH} 6.0)$ at $95^{\circ} \mathrm{C}$ for $20 \mathrm{~min}$. The sections were then sealed with $10 \%$ goat serum at $37^{\circ} \mathrm{C}$ for $30 \mathrm{~min}$. The primary antibody $(\alpha$-SMA or vimentin; 1:200) was added and the sections were incubated overnight at $4^{\circ} \mathrm{C}$. The following day, the sections were washed with PBS and then incubated with the secondary antibody (Alexa Fluor 647; 1:500; cat. no. A0468; Beyotime Institute of Biotechnology) at $25^{\circ} \mathrm{C}$ for $50 \mathrm{~min}$ in the dark. Finally, the cell nuclei were stained using DAPI (cat. no. C1002; Beyotime Institute of Biotechnology) at $37^{\circ} \mathrm{C}$ for $10 \mathrm{~min}$ in the dark.
The slides were observed under a fluorescence microscope (magnification, x200; Leica Microsystems GmbH).

Western blotting. Briefly, $20 \mathrm{mg}$ lung tissue was added to RIPA Lysis Buffer (cat. no. P0013B; Beyotime Institute of Biotechnology). The tissues were homogenised and total protein was extracted. The protein content was measured using a bicinchoninic acid assay. The protein sample was subjected to $10 \%$ SDS-PAGE with $30 \mu \mathrm{g} /$ well and then transferred onto a PVDF membrane, before and the membrane was blocked at room temperature for $2 \mathrm{~h}$ with $5 \%$ skimmed milk and washed with TBS with $100.1 \%$ Tween-20 (TBST) three times, $10 \mathrm{~min}$ per wash. The primary antibody was prepared according to the manufacturer's protocol and incubated at $4{ }^{\circ} \mathrm{C}$ for 12-18 $\mathrm{h}$. The dilution of the $\alpha$-SMA antibody used was $1: 2,000$, whilst the dilution of fibronectin, vimentin, collagen I, collagen III, TGF- $\beta 1$ and Smad3 antibodies was 1:1,000. The membranes were washed again with TBST three times for $10 \mathrm{~min}$. Subsequently, the membrane was incubated with an HRP-conjugated secondary antibody (cat. no. 3999S; Cell Signalling Technology, Inc.) at room temperature for $1 \mathrm{~h}$. Next, the membranes were washed with TBST three times for $10 \mathrm{~min}$. Signals were visualized using chemiluminescence reagent (cat. no. 170-5061; Bio-Rad Laboratories, Inc.). Densitometry analysis was performed using Image Lab software (v.5.1; Bio-Rad Laboratories, Inc.).

Reverse transcription-quantitative (RT-q)PCR. Pulmonary tissues were homogenised, and total RNA was extracted using TRIzol ${ }^{\circledR}$ reagent (cat. no. 15596026; Thermo Fisher Scientific, Inc.). The concentration of RNA was calculated, and cDNA was synthesised using Hifair ${ }^{\circledR}$ III 1st Strand cDNA Synthesis SuperMix kit (cat. no. 11141ES60; Shanghai Yeasen Biotechnology Co., Ltd.) according to the manufacturer's protocol. Hieff ${ }^{\circledR}$ qPCR SYBR Green Master Mix kit (cat. no. 11201ES03; Shanghai Yeasen Biotechnology Co., Ltd.) was used to assay the relative expression levels of TGF- $\beta 1$ and Smad3 in the pulmonary tissues. The thermocycling conditions used were as follows: $95^{\circ} \mathrm{C}$ for $5 \mathrm{~min}$; followed by 40 cycles of denaturation at $95^{\circ} \mathrm{C}$ for $10 \mathrm{sec}$, annealing at $60^{\circ} \mathrm{C}$ for $20 \mathrm{sec}$ and elongation at $72^{\circ} \mathrm{C}$ for $20 \mathrm{sec}$. The average expression of target genes and GAPDH was calculated using the $\mathrm{Cq}$ values. In each group, the relative amount of gene expression was calculated using the $2^{-\Delta \Delta \mathrm{Cq}}$ value of the model group (28). Primers for TGF- $\beta 1$ and Smad3 were synthesised by Sangon Biotech Co., Ltd. The sequences of the primers were TGF- $\beta 1$ forward, 5'-CCAGATCCTGTCCAAACTAAG G-3' and reverse, 5'-CTCTTTAGCATAGTAGTCCGCT-3' Smad3 forward, 5'-ATTCCATTCCCGAGAACACTAA-3' and reverse, 5'-TAGGTCCAAGTTATTGTGTGCT-3'; GAPDH forward, 5'-GGTTGTCTCCTGCGACTTCA-3'; and reverse, 5'-TGGTCCAGGGTTTCTTACTCC-3'.

Statistical analysis. All results are based on triplicate experiments and presented as the mean \pm standard deviation (SD). Statistical analysis was performed using GraphPad Prism 8 software (GraphPad Software, Inc.). Inflammation and fibrosis scores were compared using Kruskal-Wallis test, followed by the Dunn post hoc test. One- or two-way analysis of variance followed by Tukey's test was used to determine statistical 
Table I. Composition of Maiwei Yangfei decoction.

\begin{tabular}{lllllrrrl}
\hline $\begin{array}{l}\text { Compound } \\
\text { number }\end{array}$ & Component & Formula & Adduct & $\begin{array}{c}\text { Exact } \\
\text { Mass }\end{array}$ & $\begin{array}{c}\text { Retention } \\
\text { time (min) }\end{array}$ & $\begin{array}{c}\text { Mass/charge } \\
\text { ratio }\end{array}$ & $\begin{array}{c}\text { Parts per } \\
\text { million }\end{array}$ & Chinese name \\
\hline 1 & Succinic acid & $\mathrm{C}_{4} \mathrm{H}_{6} \mathrm{O}_{4}$ & {$[\mathrm{M}-\mathrm{H}]^{-}$} & 117.01823 & 1.20 & 191.01891 & -3.548 & Ban xia \\
2 & Ephedrine & $\mathrm{C}_{10} \mathrm{H}_{15} \mathrm{NO}$ & {$[\mathrm{M}+\mathrm{H}]^{+}$} & 166.12264 & 2.75 & 447.09247 & 0.417 & Ma huang \\
3 & Ferulic acid & $\mathrm{C}_{10} \mathrm{H}_{10} \mathrm{O}_{4}$ & {$[\mathrm{M}-\mathrm{H}]^{-}$} & 193.04953 & 3.59 & 193.04967 & 0.698 & Dang gui \\
4 & Hesperidin & $\mathrm{C}_{28} \mathrm{H}_{34} \mathrm{O}_{15}$ & {$[\mathrm{M}+\mathrm{H}]^{+}$} & 611.19704 & 3.70 & 611.19733 & 0.464 & Chen pi \\
5 & Rosmarinic acid & $\mathrm{C}_{18} \mathrm{H}_{16} \mathrm{O}_{8}$ & {$[\mathrm{M}-\mathrm{H}]^{-}$} & 359.07614 & 3.78 & 359.07700 & 3.470 & Zi su zi \\
6 & Lobetyolin & $\mathrm{C}_{20} \mathrm{H}_{28} \mathrm{O}_{8}$ & {$[\mathrm{M}+\mathrm{Na}]^{+}$} & 419.16763 & 4.00 & 419.16718 & -0.969 & Dang shen \\
7 & Baicalin & $\mathrm{C}_{21} \mathrm{H}_{18} \mathrm{O}_{11}$ & {$[\mathrm{M}+\mathrm{H}]^{+}$} & 447.09218 & 4.02 & 447.09247 & 0.631 & Huang qin \\
8 & Glycyrrhizic acid & $\mathrm{C}_{42} \mathrm{H}_{62} \mathrm{O}_{16}$ & {$[\mathrm{M}+\mathrm{H}]^{+}$} & 823.41106 & 5.48 & 823.41187 & 0.981 & Gan cao \\
9 & Schisandrin & $\mathrm{C}_{24} \mathrm{H}_{32} \mathrm{O}_{7}$ & {$[\mathrm{M}+\mathrm{H}]^{+}$} & 433.22207 & 6.41 & 433.22208 & 0.000 & Wu wei zi \\
10 & Asarinin & $\mathrm{C}_{20} \mathrm{H}_{18} \mathrm{O}_{6}$ & {$[\mathrm{M}-\mathrm{H}]^{-}$} & 353.10196 & 6.75 & 353.10315 & 3.357 & Xi xin \\
11 & Ruscogenin & $\mathrm{C}_{27} \mathrm{H}_{42} \mathrm{O}_{4}$ & {$[\mathrm{M}+\mathrm{H}]^{+}$} & 431.31558 & 7.40 & 431.20694 & 0.774 & Mai dong \\
12 & Shionone & $\mathrm{C}_{30} \mathrm{H}_{50} \mathrm{O}$ & {$[\mathrm{M}+\mathrm{H}]^{+}$} & 427.39344 & 13.45 & 427.39380 & 0.836 & Zi wan \\
\hline
\end{tabular}

significance. $\mathrm{P}<0.05$ was considered to indicate a statistically significant difference.

\section{Results}

Primary components in MWYF. MWYF consists of 12 Chinese herbal medicines, indicating a complex composition. Amino acids, flavonoids, phenols, terpenes and organic acids were identified in the MWYF decoction and LC-MS was used for the analysis of these chemical ingredients. Under optimised LC-MS conditions, the primary components of MWYF were isolated and detected. The typical components are shown in Table I. The peak signals for the 12 chemicals were identified according to the retention time, mass of fragment ions (mass/valence), the wavelength of UV absorption. The total ion flow of these components is shown in Fig. 1. In the chromatograms, succinic acid, ephedrine, ferulic acid, esperidin, rosmarinic acid, lobetyolin, baicalin, glycyrrhizic acid, schizandrin, asarinin, ruscogenin and shionone were detected.

Body weight. To assess the effects of MWYF fibrosis in vivo, mice were instilled with BLM to induce lung fibrosis. MWYF at doses of 20,40 or $60 \mathrm{~g} / \mathrm{kg} /$ day were orally given to the mice for 21 days (Fig. 2A). The weights of the mice were markedly reduced within 3 days of model construction, with the exception of the control group. However, 1 week after the model was constructed, the weight of mice in all groups continued to recover (Fig. 2B). Compared with those in the control group, the terminal mice weights in the model group were significantly reduced. Although the body weights of mice in the treatment group increased, no statistical difference could be observed compared with those in the model group (Fig. 2C).

Pulmonary alveolitis and PF scores. Pulmonary alveolitis and PF were scored based on the H\&E and Masson staining images to evaluate the degree of inflammation and fibrosis. Using H\&E staining, the structure of the mouse lung tissues in the control group was clear, the morphology of pulmonary alveoli was normal, the walls of the pulmonary alveoli were thin and no inflammatory cell infiltration was observed in the interstitial lung (Fig. 3A). In mice in the model group, the structure of the pulmonary alveoli was severely damaged. Several pulmonary alveoli had collapsed, merged and had become necrotic (Fig. 3A). The walls of the pulmonary alveoli were thickened and exhibited large degrees of inflammatory cell infiltration (Fig. 3A). Compared with that in the model group, in the high dose MWYF group, marked improvements were observed, with the structure of pulmonary alveoli almost intact, in addition to fewer collapsed pulmonary alveoli or parenchymal lesions and a reduced degree of inflammatory cell infiltration in the cavity of pulmonary alveoli (Fig. 3A). These parameters were also improved to a certain extent in the low and medium dose MWYF groups (Fig. 3A).

In the control group, Masson staining demonstrated that the structure of pulmonary alveoli tissues was regular and arranged in an orderly manner, with only a small number of fine light blue fibres observed (Fig. 3A). In the lung tissues of the model group, large quantities of blue collagen were deposited in the alveolar septum and in the pulmonary mesenchyme (Fig. 3A). Compared with that in the model group, significant improvements were observed in the high dose MWYF group, with blue collagen deposition markedly alleviated in the lung tissues. A degree of improvement albeit to a reduced extent was also observed in the low and medium dose MWYF groups (Fig. 3A).

The inflammation score was calculated to be significantly higher in the model group compared with that in the normal control group (Fig. 3B). In the high dose MWYF group, the pulmonary alveolitis score was significantly reduced compared with the scores of the model group (Fig. 3B). Compared with that in the control group, the PF score was significantly higher in the model group (Fig. 3C). The mouse PF scores in the high dose MWYF group were also significantly lower compared with that in the model group (Fig. 3C).

Collagen content in the pulmonary tissues. The typical pathological change during PF is characterised by the deposition of collagen in the pulmonary fibres, particularly collagen I and 

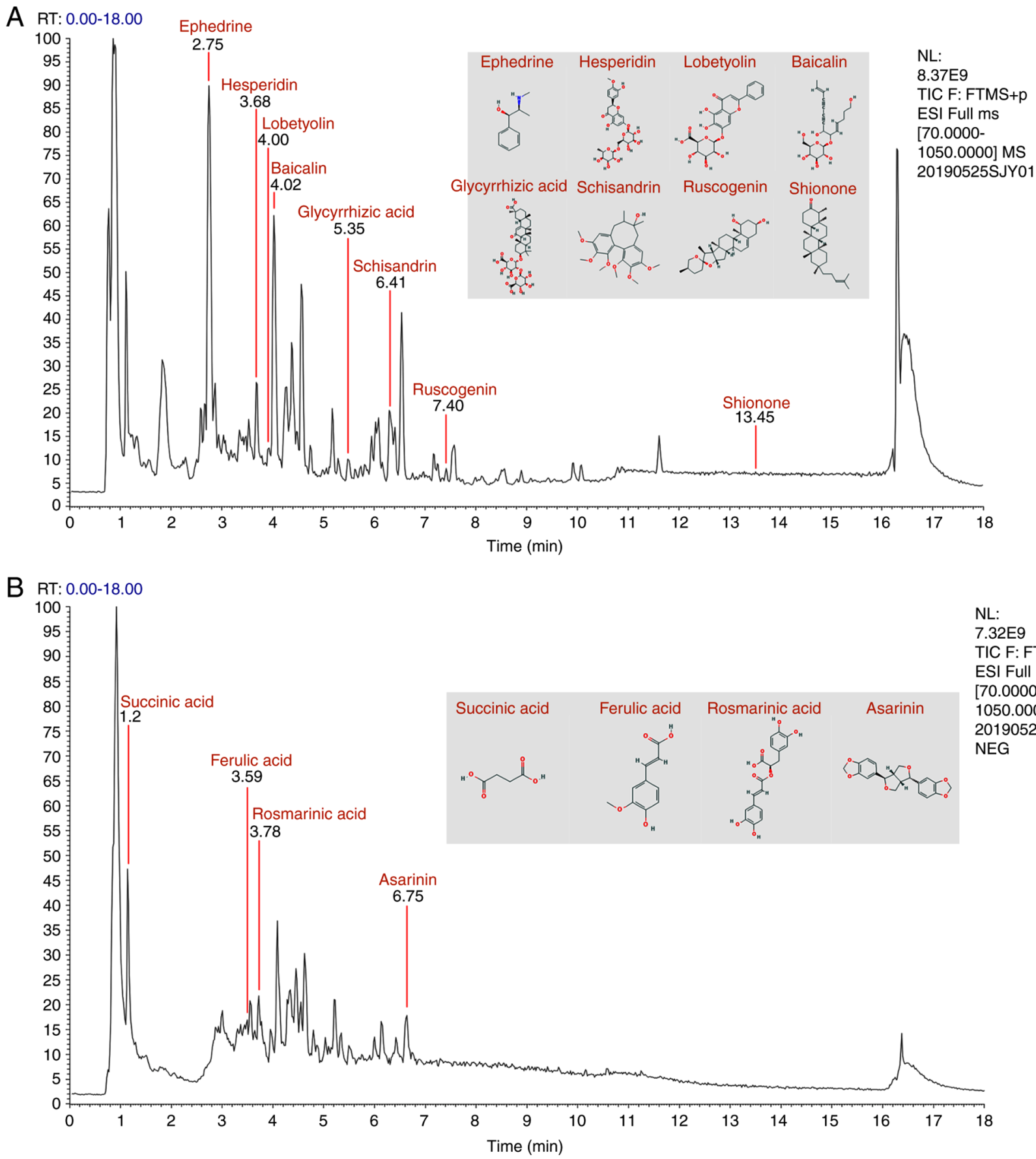

Figure 1. Elementary particle flow graph chromatogram of the Maiwei Yangfei decoction. Monitoring in (A) positive ion mode and (B) negative ion mode. In the chromatograms, succinic acid, ephedrine, ferulic acid, esperidin, rosmarinic acid, lobetyolin, baicalin, glycyrrhizic acid, schizandrin, asarinin, ruscogenin and shionone were detected.

collagen III (29). Compared with that in the control group, the expression of collagen I and collagen III were significantly higher in the model group (Fig. 4A-C). By contrast, compared with that in the model group, the expression of collagen I and collagen III were reduced to a certain degree in the lung tissues of the MWYF-treated groups, but a significant reduction was only observed in the high dose MWYF group (Fig. 4A-C).

HYP is the primary component of collagen, where its content is an effective indicator for evaluating collagen deposition in lung tissues (30). PYD is a key enzyme involved in collagen synthesis, which can be used to effectively indicate the state of collagen deposition (31). Compared with those in the control group, the levels of collagen I, HYP and PYD were significantly higher in the lung tissues of the model group, as indicated by ELISA data. By contrast, in the low, medium and high dose MWYF groups, the levels of collagen I, HYP and PYD were reduced to a certain degree compared with those in the model group (Fig. 4D-F), with the reduction becoming significant in the high dose MWYF group (Fig. 4D-F). Compared with those in the control group, western blotting demonstrated that the expression levels of collagen I and collagen III were significantly increased in the model group. By contrast, in the low, medium and high dose MWYF groups, the expression levels of collagen I and collagen III were 


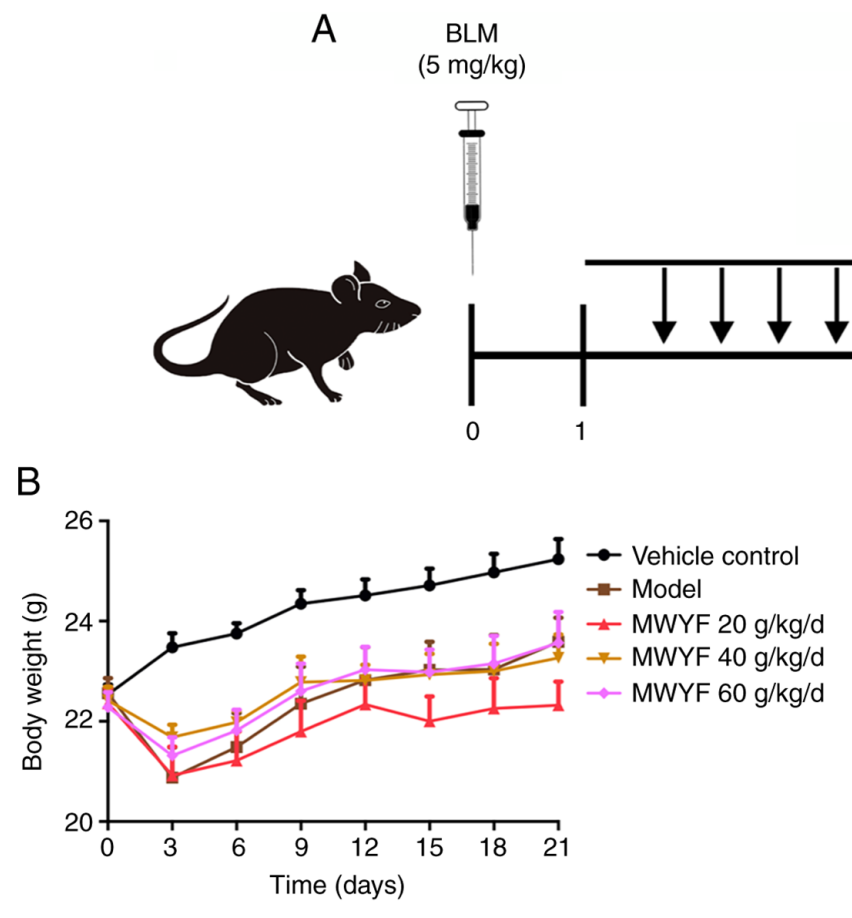

MWYF $(20,40,60 \mathrm{~g} / \mathrm{kg} / \mathrm{d})$

Daily administration

C

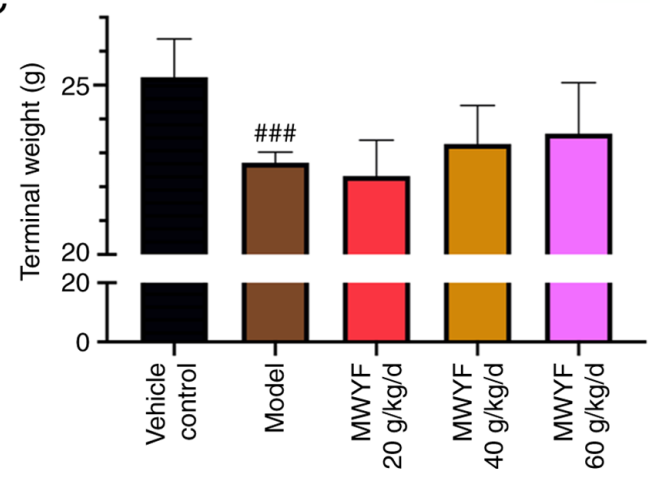

Figure 2. Effects of MWYF on mice body weight in the different treatment groups. (A) Scheme of the experimental setup. After bleomycin exposure, mice received MWYF daily and were sacrificed on day 21. (B) Body weight measurement after BLM injection and various treatment regimens over the 21-day period. (C) Effects of MWYF on the terminal body weight in mice with BLM-induced pulmonary fibrosis. All data are expressed as mean \pm SD (n=10),

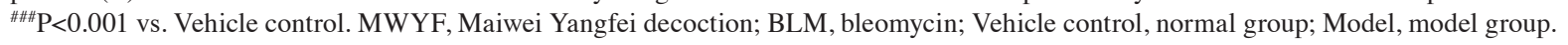

A

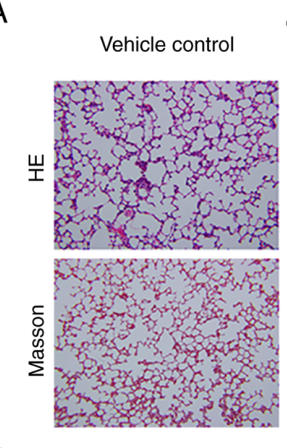

B

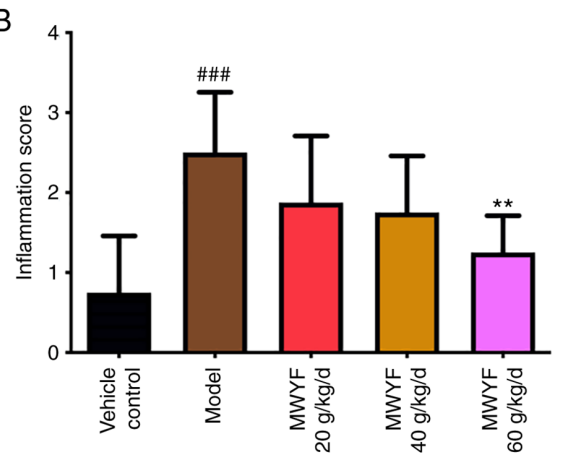

Bleomycin
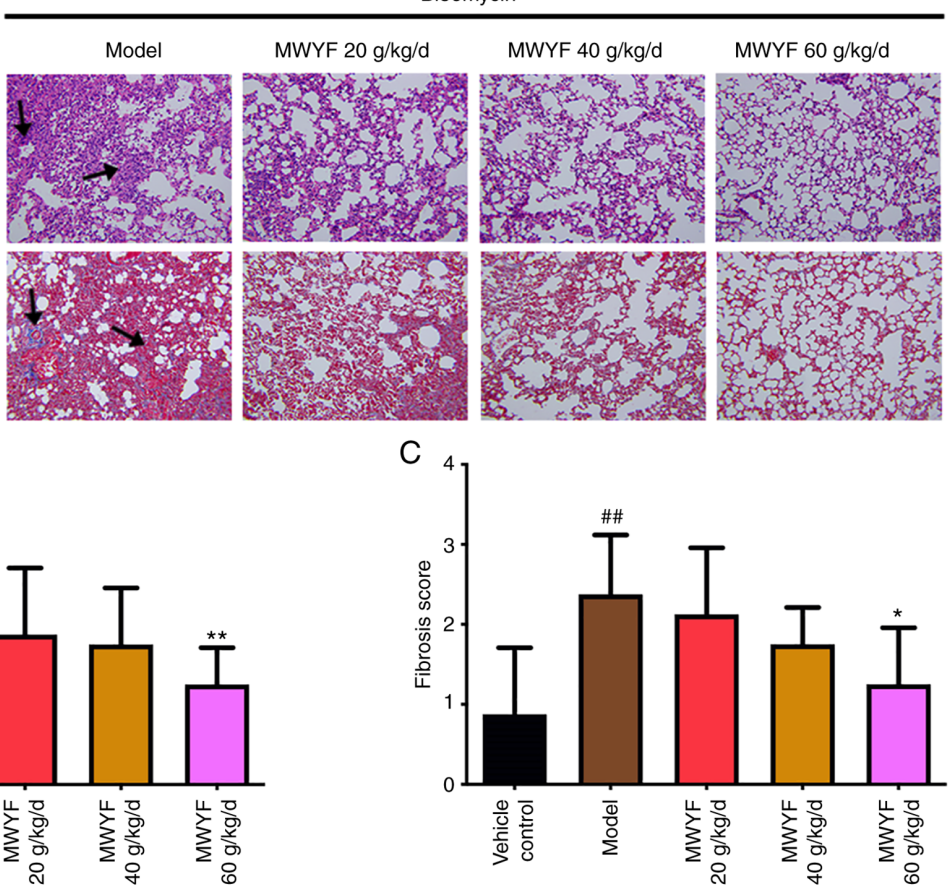

Figure 3. Effects of MWYF on the histopathological changes in lung tissues of mice with BLM-induced pulmonary fibrosis. (A) Lung sections were stained with H\&E or Masson Trichrome. Magnification, x200. (B) Effects of MWYF on the alveolitis score. (C) Effects of MWYF on the fibrosis score. All data are expressed as mean $\pm \mathrm{SD}(\mathrm{n}=10),{ }^{\# \#} \mathrm{P}<0.001$ and ${ }^{\# \# /} \mathrm{P}<0.01$ vs. Vehicle control. ${ }^{*} \mathrm{P}<0.05$ and ${ }^{* *} \mathrm{P}<0.01$ vs. Model. MWYF, Maiwei Yangfei decoction; Vehicle control, normal group; Model, model group.

reduced to a certain degree compared with those in the model group, with the reduction becoming significant in the medium and high dose MWYF groups (Fig. 4G and H).
Expression of related marker proteins in the pulmonary tissues. In PF, the main pathological changes observed are the proliferation of pulmonary fibroblasts and the differentiation 
A

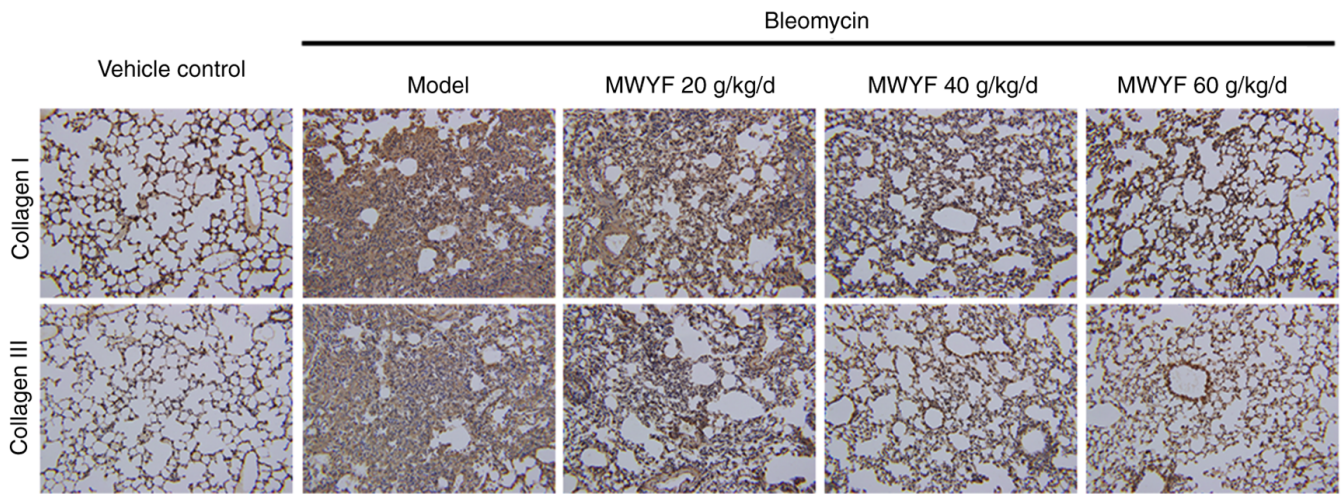

B

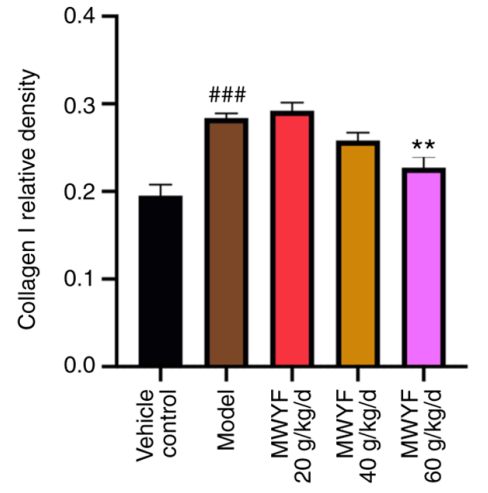

C

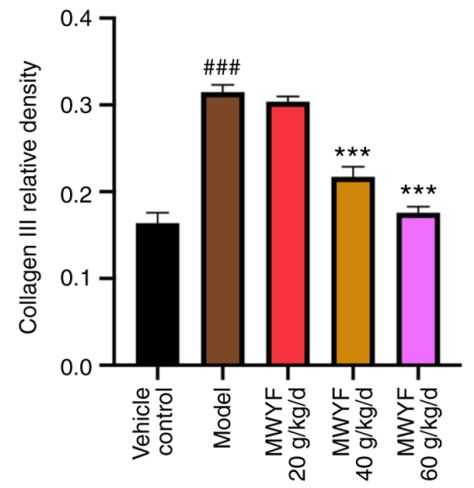

$\mathrm{D}$

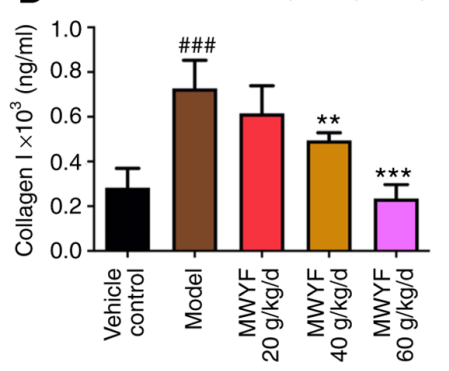

E

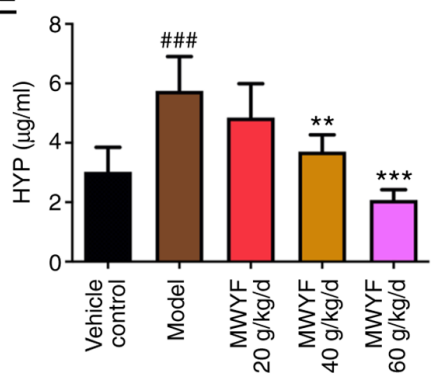

F

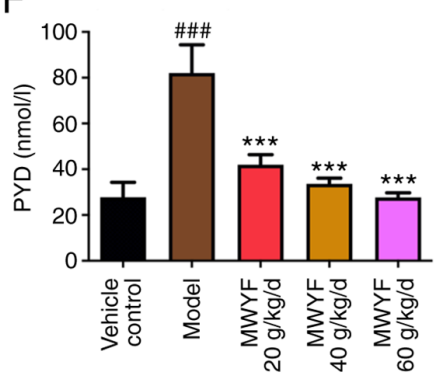

G

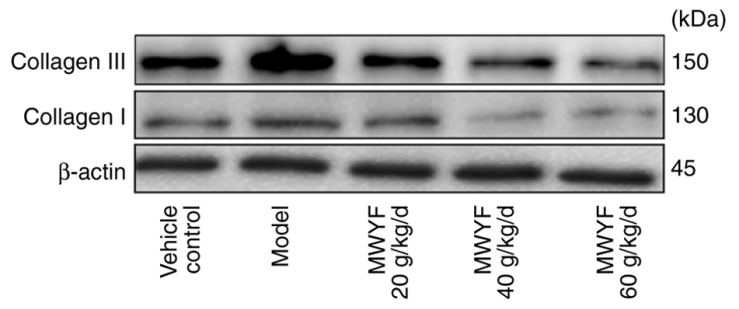

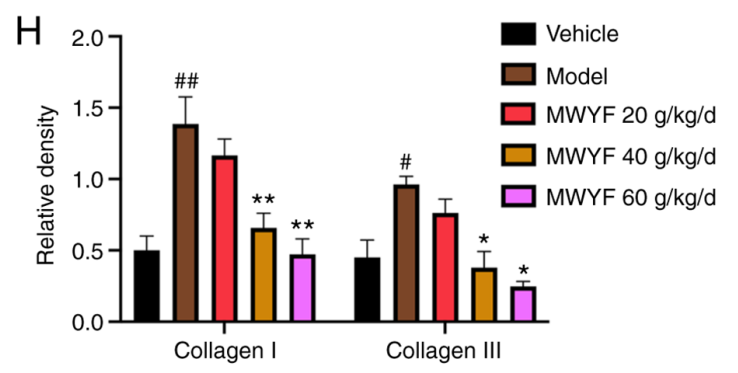

Figure 4. Effects of MWYF on collagen content in mice with BLM-induced pulmonary fibrosis. (A) Expression of collagen I and collagen III in the lung tissues was measured by immunohistochemistry. Magnification, x200. Quantitative results of immunohistochemical staining for (B) collagen I and (C) collagen III. Expression of (D) collagen I, (E) HYP and (F) PYD in the lung tissues was detected by ELISA. (G) Expression of collagen I and collagen III were measured by western blotting, (H) which was quantified. All data are expressed as mean $\pm \mathrm{SD}(\mathrm{n}=10) .{ }^{\#} \mathrm{P}<0.05,{ }^{\# \#} \mathrm{P}<0.01$ and ${ }^{\# \# /} \mathrm{P}<0.001$ vs. Vehicle; ${ }^{*} \mathrm{P}<0.05$, ${ }^{* *} \mathrm{P}<0.01$ and ${ }^{* * *} \mathrm{P}<0.001$ vs. Model. MWYF, Maiwei Yangfei decoction; Vehicle control, normal group; Model, model group; HYP, hydroxyproline; PYD, pyridinoline.

of fibroblasts into myofibroblasts (32), $\alpha$-SMA is linked to the activation of myofibroblasts (33), whilst vimentin is related to the proliferation of fibroblasts (34) and fibronectin is a component of the ECM (35). Therefore, the expression levels of these proteins were assessed to evaluate the degree of PF using immunofluorescence and western blotting. Based on the results of the immunofluorescence analysis, in the model group, the expression levels of $\alpha$-SMA and vimentin were increased significantly when compared with those in the control group. By contrast, treatment with MWYF decoction at all three doses significantly decreased the expression levels of these two proteins, with the magnitude particularly high in the medium and high dose MWYF groups (Fig. 5A-C). The results of western blotting indicated that the expression levels of fibronectin, vimentin and $\alpha$-SMA were significantly increased in the model group compared with those in the control group. By contrast, MWYF 
A
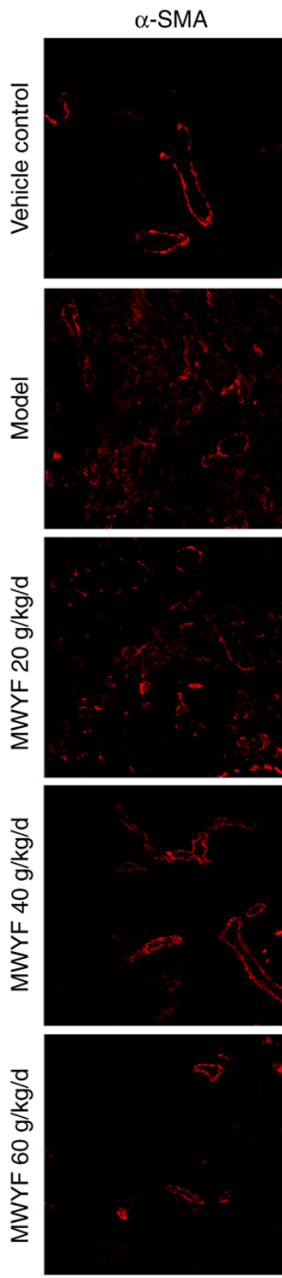

$\mathrm{B}$

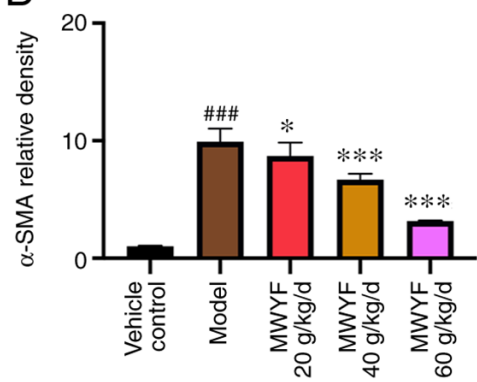

E

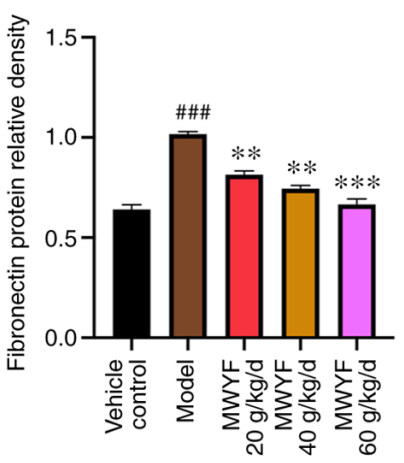

DAPI
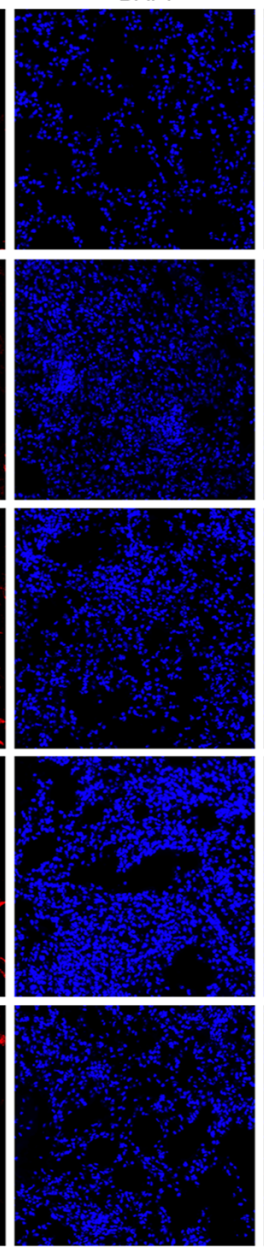

C

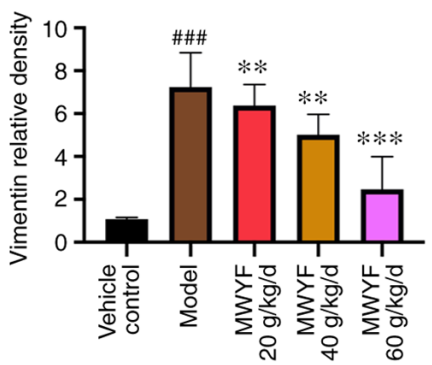

$\mathrm{F}$
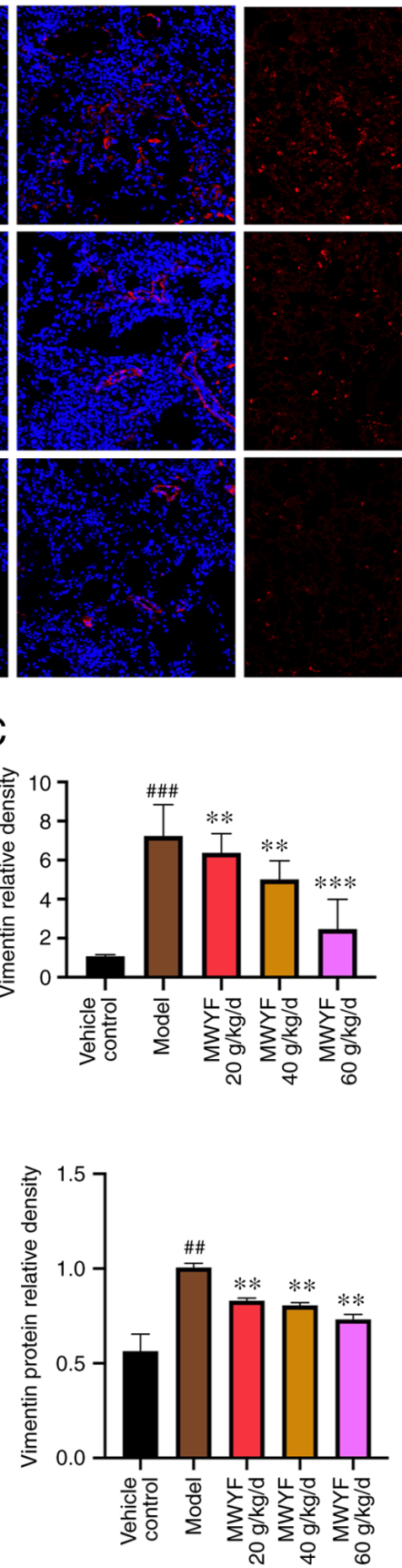

DAPI
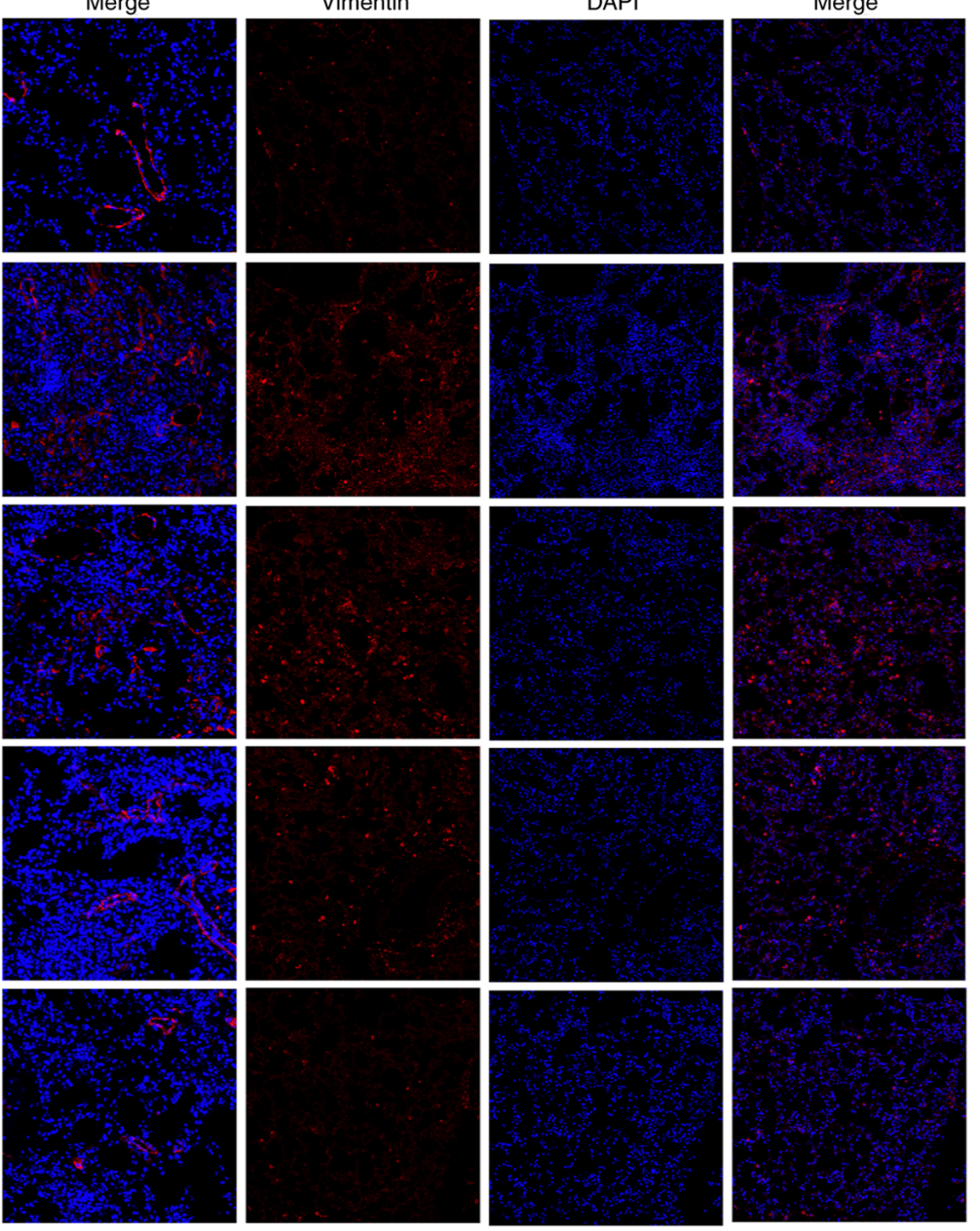

D

(kDa)
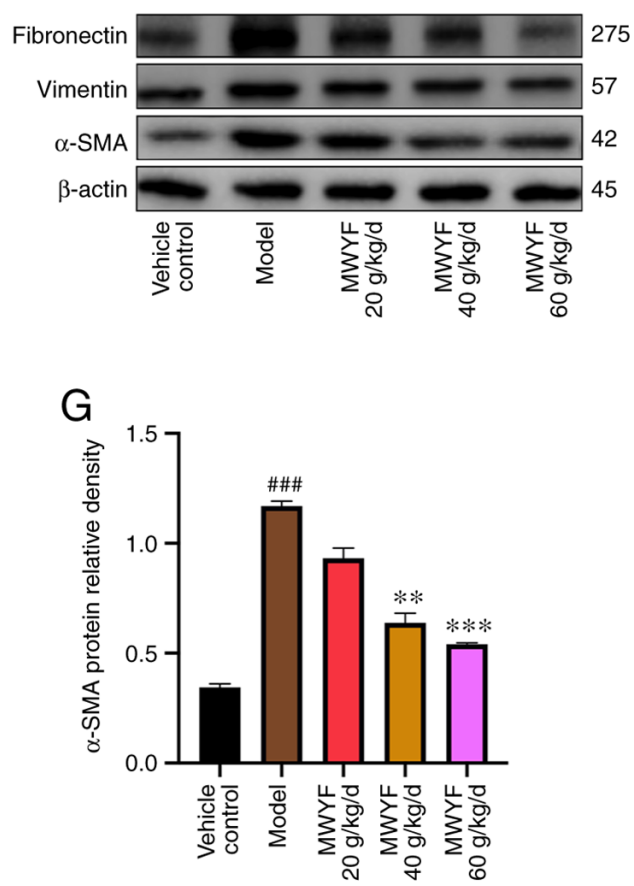

Figure 5. Effects of MWYF on the expression of marker proteins for fibrosis in pulmonary tissues of mice with BLM-induced pulmonary fibrosis. The red fluorescence represents the expression of $\alpha$-SMA and vimentin, whereas the blue fluorescence represents cell nuclei stained with DAPI. (A) Expression of $\alpha$-SMA and vimentin in the lung tissues were measured by immunofluorescence. Magnification, x200. (B) Quantitative results of immunofluorescence analysis of (B) $\alpha$-SMA and (C) vimentin. (D) Expression of fibronectin, vimentin and $\alpha$-SMA proteins were measured by western blotting. Quantitative results of (E) fibronectin, (F) vimentin and $(\mathrm{G}) \alpha$-SMA protein expression. All data are expressed as mean $\pm \mathrm{SD}(\mathrm{n}=10)$. ${ }^{\# \#} \mathrm{P}<0.001$ and ${ }^{\# \# \#} \mathrm{P}<0.01$ vs. Vehicle control. ${ }^{*} \mathrm{P}<0.05$, ${ }^{* *} \mathrm{P}<0.01$ and ${ }^{* * *} \mathrm{P}<0.001$ vs. Model. MWYF, Maiwei Yangfei decoction; Vehicle control, normal group; Model, model group; $\alpha$-SMA, $\alpha$-smooth muscle actin. 
A

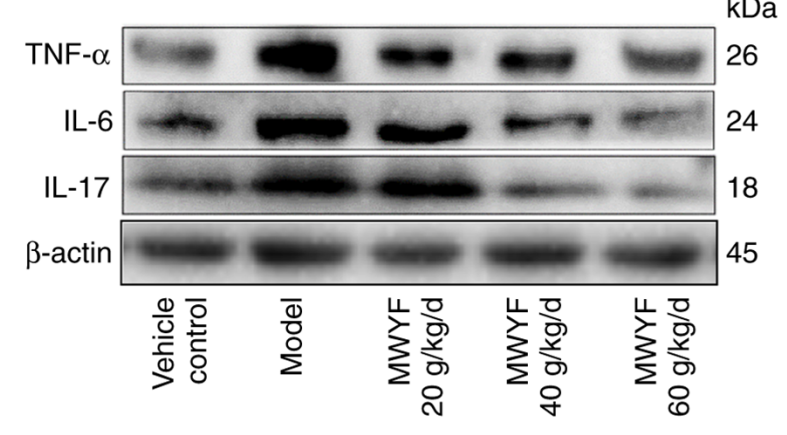

B

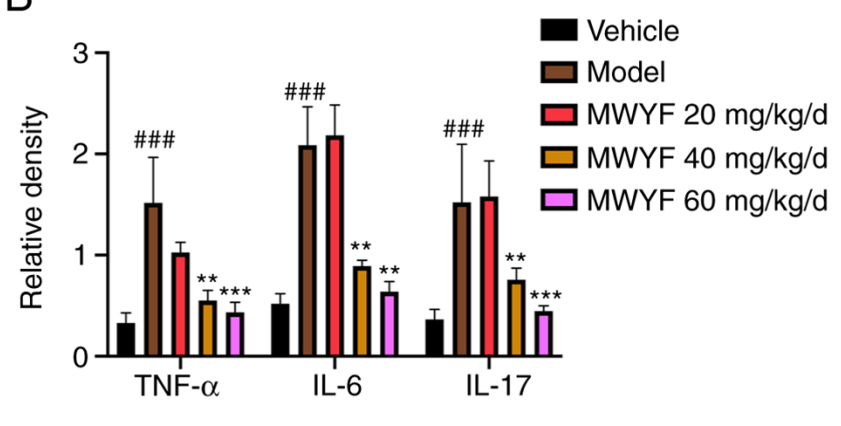

C

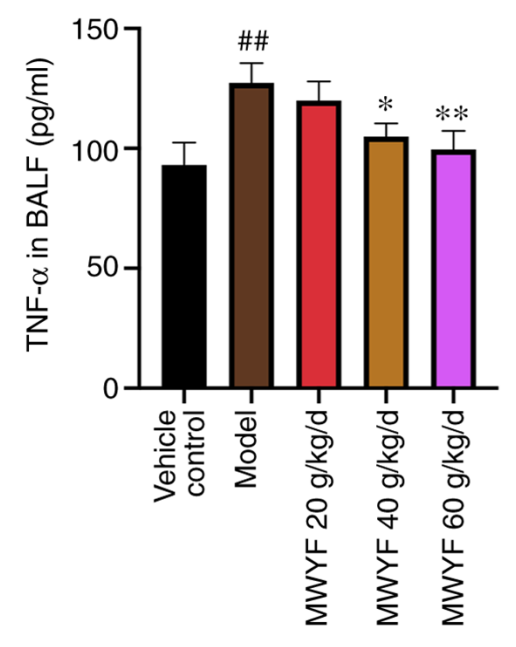

D

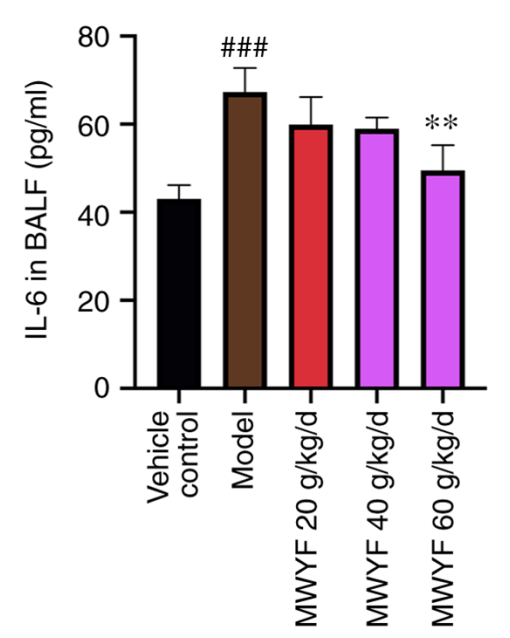

E

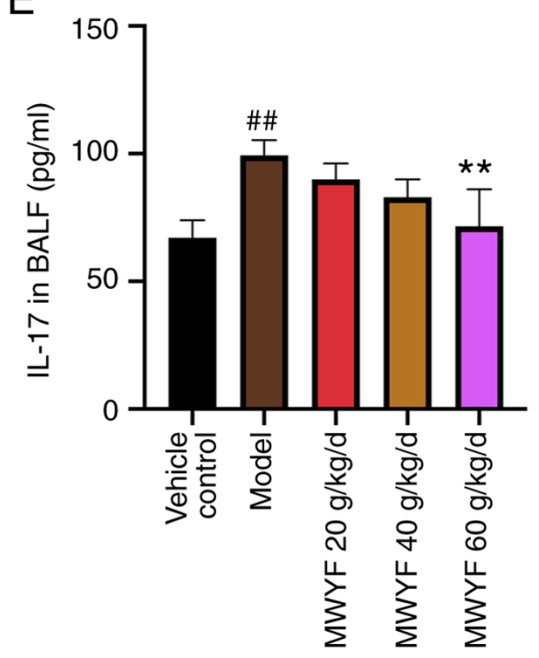

Figure 6. Effects of MWYF on the levels of inflammatory factors in mice with bleomycin-induced pulmonary fibrosis. (A) Western blot analysis of the protein expression of TNF- $\alpha$, IL-6 and IL-17 in the lung tissues. (B) Quantitative analysis of TNF- $\alpha$, IL-6, and IL-17 protein expression. Levels of (C) TNF- $\alpha$, (D) IL-6 and (E) IL-17 in the BALF were detected by ELISA. All data are expressed as mean $\pm \mathrm{SD}(\mathrm{n}=10)$. ${ }^{\# \#} \mathrm{P}<0.001$ and ${ }^{\# \# \#} \mathrm{P}<0.01$ vs. Vehicle control. ${ }^{*} \mathrm{P}<0.05,{ }^{* *} \mathrm{P}<0.01$ and ${ }^{* * *} \mathrm{P}<0.001$ vs. Model. MWYF, Maiwei Yangfei decoction; Vehicle control, normal group; Model, model group; BALF, bronchial alveolar lavage fluid.

administration markedly reduced the expression levels of fibronectin, vimentin and $\alpha$-SMA, with medium and high MWYF dose exerting significant reversals (Fig. 5D-G).

Levels of inflammatory factors in the pulmonary tissues and BALF. Cytokines serve key roles in the occurrence and development of PF (36). It has been previously shown that TNF- $\alpha$, IL- 6 and IL-17 can promote the progression of PF through inflammatory pathways (37-39). To assess the role of MWYF in TNF- $\alpha$, IL-6 and IL-17, the expression profile of these three cytokines in pulmonary tissues was determined using western blotting whereas TNF- $\alpha$, IL- 6 and IL-17 levels were detected in BALF using ELISA. Western blotting indicated that compared with the control group, the expression of TNF- $\alpha$, IL- 6 and IL-17 proteins in the model group was increased. Compared with the model group, as the concentration of MWYF increased, the protein expression decreased (Fig. 6A and B). Compared with those in the control group, the levels of TNF- $\alpha$, IL- 6 and IL-17 were significantly increased in the BALF of the model group (Fig. 6C-E). By contrast, in the high dose MWYF group, the levels of TNF- $\alpha$, IL- 6 and IL-17 were significantly reduced compared with that in the model group (Fig. 6C-E). This suggests that MWYF exerted its beneficial effects on PF by reducing the expression of inflammatory cytokines.

Expression of TGF- $\beta 1$ and Smad3 in pulmonary tissues. TGF- $\beta 1$ serves a key role in the development of PF (40). TGF- $\beta 1$ promotes the deposition of ECM by increasing the transcriptional levels of collagen-related genes via Smad3, thereby accelerating the differentiation of pulmonary fibroblasts into myofibroblasts and exacerbating the degree of PF by promoting the apoptosis of the type-II epithelial cells $(41,42)$. In the present study, the expression levels of TGF- $\beta 1$ and Smad3 proteins and mRNA were measured using western blotting and RT-qPCR, respectively. High- and medium dose MWYF treatment significantly decreased the expression of TGF- $\beta 1$ and Smad 3 in mouse lung tissues at both the transcriptional and translational levels compared with that in the model group (Fig. 7).

\section{Discussion}

Pulmonary interstitial fibrosis is a connective tissue disease that is primarily characterized by dry cough and dyspnoea with an unknown pathogenesis (43). The most severe pathological traits appear to be the aberrant proliferation of fibroblasts, 
A

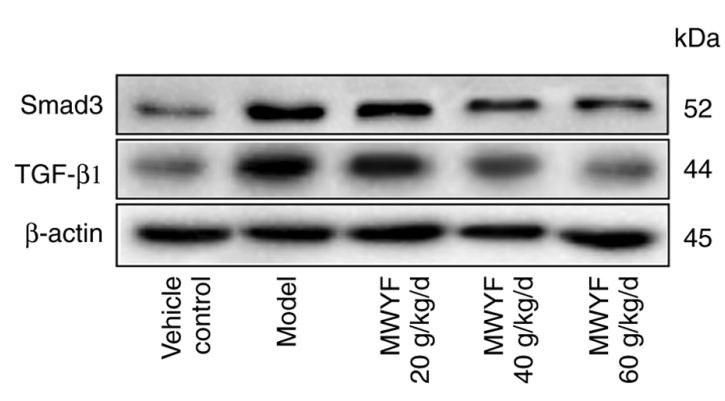

C

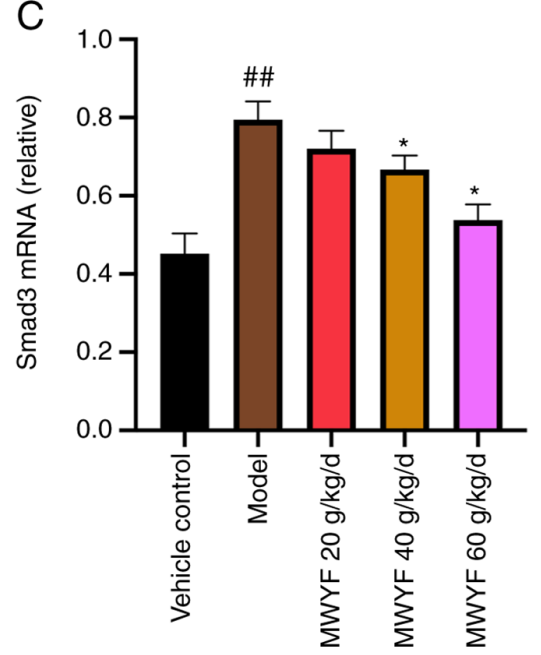

B

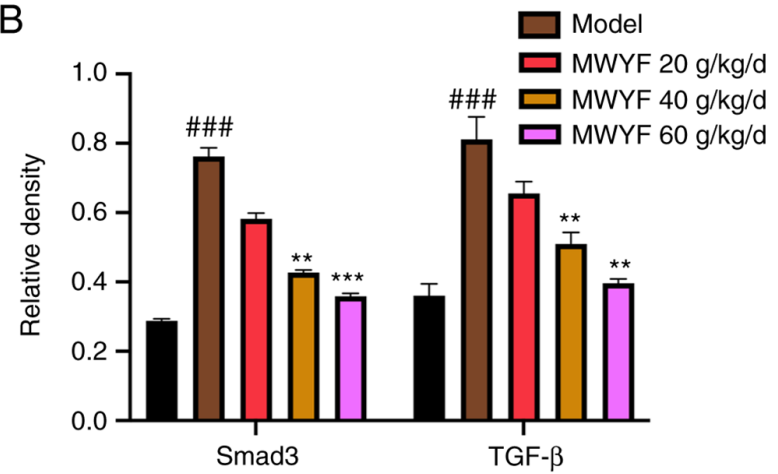

D

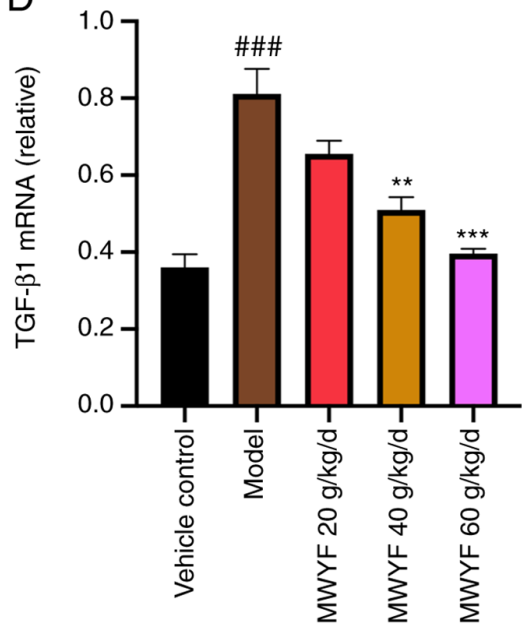

Figure 7. Effects of MWYF on the expression of TGF- $\beta 1$ and Smad3 in the pulmonary tissue of mice with BLM-induced pulmonary fibrosis. (A) The expression of TGF- $\beta 1$ and Smad 3 in the lung tissues were measured by western blotting. (B) Quantitative analysis of TGF- $\beta 1$ and Smad 3 expression. Reverse transcription-quantitative PCR was used to measure the relative expression of (C) Smad3 and (D) TGF- $\beta 1$. All data are expressed as mean \pm SD ( $=10$ ). ${ }^{\# \#} \mathrm{P}<0.001$ and ${ }^{\# \# \#} \mathrm{P}<0.01$ vs. Vehicle control group. ${ }^{*} \mathrm{P}<0.05,{ }^{* *} \mathrm{P}<0.01$ and ${ }^{* * *} \mathrm{P}<0.001$ vs. Model group. MWYF, Maiwei Yangfei decoction; Vehicle control, normal group; Model, model group.

differentiation of fibroblasts into myofibroblasts and the excessive deposition of ECM, all of which eventually lead to the failure of lung function $(44,45)$. Although nintedanib and pirfenidone can delay the progression of $\mathrm{PF}$, they are expensive and cause notable adverse reactions, reducing their efficacy (46). Therefore, discovery of novel agents and then confirming their efficacy remain imperative for patients with PF. Therefore, in the present study, a BLM-induced pulmonary mouse PF model was established, following which the efficacy of MWYF was assessed with the underlying mechanism of action investigated.

There are four types of collagens in lung tissues, where collagen I and collagen III are the most abundant (47). Collagenous fibers are an aggregated form of collagen secreted by the fibroblasts (48). Collagen primarily contains HYP, an amino acid present in the body's collagenous fibre (49). Furthermore, HYP is an important indicator used for estimating the metabolism of collagenous tissues and the degree of pulmonary interstitial fibrosis (50). Intermolecular cross-linking is an important post-translational modification during collagen formation (50). Results from the present study demonstrated that a high dose MWYF decoction can reduce collagen I, collagen III, HYP and PYD expression, suggesting a protective role for the MWYF decoction in BLM-induced $\mathrm{PF}$ in mice.
$\alpha$-SMA is a marker of myofibroblast activation (51). The expression of $\alpha$-SMA in the cytoplasm allows cellular contractility, which is closely associated with tissue fibrosis (51). In addition, the expression level of $\alpha$-SMA is positively associated with the degree of PF (52). ECM deposition is the primary cause of PF, where fibronectin is an important component (3). Excessive deposition of fibronectin can result in the formation of scars and acceleration of fibrosis. Vimentin is normally expressed in mesenchymal tissues, with little to no expression in epithelial cells (53). Therefore, vimentin can be used as a protein marker of fibroblasts. The expression of $\alpha$-SMA and vimentin in lung tissues was determined using immunofluorescence analysis in the present study. The immunofluorescence results indicated that the proportion of cells exhibiting positive $\alpha$-SMA and vimentin expression was significantly higher in the model group compared with that in the control group. When different concentrations of the MWYF decoction were administered, the proportion of $\alpha$-SMA- and vimentinpositive cells was reduced to a certain degree, particularly in the high dose MWYF group.

The inflammatory response in the pulmonary alveoli is one of the primary causes of inflammatory cytokine release (54). TNF- $\alpha$ is a proinflammatory cytokine that can stimulate neutrophilic granulocytes and eosinophils to 


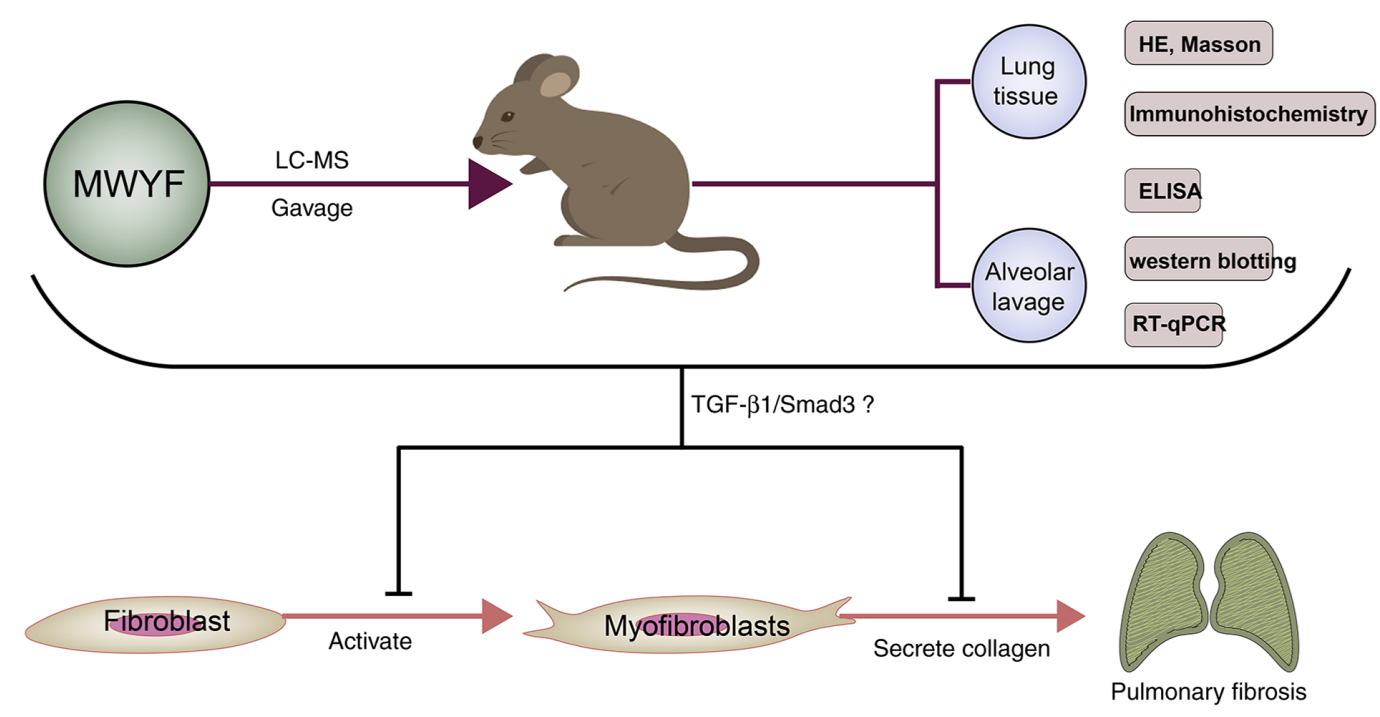

Figure 8. Mechanism research diagram. MWYF can alleviate lung inflammation, reduce collagen deposition and decrease the expression level of PF marker proteins, and it may be potent in ameliorating PF via the TGF- $31 /$ Smad3 signaling pathway. MWYF, Maiwei Yangfei decoction. LC-MS, liquid chromatography-mass spectrometry; RT-qPCR, reverse transcription-quantitative PCR; PF, pulmonary fibrosis.

produce superoxides and release lysosomal enzymes (55). Furthermore, TNF- $\alpha$ can accelerate the progression of fibrosis (55). IL-6 is also a proinflammatory cytokine that can accelerate the early alveolytic response through the chemotaxis, infiltration and aggregation of inflammatory cells (56). IL-17 is another proinflammatory cytokine that can activate various cytokines, fibroblasts, endothelial cells and epithelial cells to promote the formation of PF (57). In the present study, the PF mouse model used appeared to have mimicked the acute pulmonary injury model, as an inflammatory response was consistently observed throughout the entire modelling process. Therefore, although the lung tissues were collected 21 days after model construction, a compensatory inflammatory response remained. Results from the present study demonstrated that MWYF reduced the levels of TNF- $\alpha$, IL-6 and IL-17 in the BALF of mice with PF, suggesting that the MWYF decoction could delay the development of PF by inhibiting the inflammatory response.

TGF- $\beta 1 / \mathrm{Smad} 3$ is considered to be a classical signalling pathway associated with PF (58). TGF- $\beta 1$ has been previously shown to directly promote fibrosis (59). It promotes the proliferation, differentiation and secretion of interstitial cells, induces the differentiation of fibroblasts into myofibroblasts, thereby increasing the deposition of ECM (60). Therefore, it is considered to be an inducer and promoter of fibrosis. Smad proteins belong to a family of unique intracellular signal transduction molecules that can interact with various transcription factors in cell-specific patterns (61). This in turn modulates the transcription of target genes, such as collagen, to promote the formation of fibrosis (60). TGF- $\beta 1$ activation results in the phosphorylation of Smad3 and its subsequent entry into the cell nuclei, which then activate the expression of a series of genes to promote the differentiation of fibroblasts into pulmonary fibroblasts that express contractile proteins, such $\alpha$-SMA (62). In the present study, the expression levels of TGF- $\beta 1$ and Smad3 were increased significantly after model construction. However, this was reversed after MWYF treatment, suggesting that
MWFY likely alleviated BLM-induced PF in mice via the TGF- $\beta 1 /$ Smad3 signalling pathway.

In conclusion, in vivo analysis of the effects of MWYF treatment was performed, where it was shown to be effective in alleviating the pathology in mice with BLM-induced PF. This was mediated by reducing collagen deposition, highlighting its potentially therapeutic and protective effects. The underlying mechanism of the effects of the MWYF decoction at least partially involved inhibition of the TGF- $\beta 1 / \mathrm{Smad} 3$ signalling pathway (Fig. 8). However, further study of the mechanisms underlying the modulation by MWYF treatment in PF is required. In addition, due to the diversity and variability contained within MWYF, the results and conclusions observed in the present study require further verification to confirm the potential clinical value of MWYF.

\section{Acknowledgements}

Not applicable.

\section{Funding}

The present study was financially funded by the National Natural Science Foundation of China (grant no. 82074358) and Graduate Student Scientific Research Innovation Projects in Jiangsu Province (grant no. KYCX21_1706).

\section{Availability of data and materials}

The datasets used and/or analyzed during the current study are available from the corresponding author on reasonable request.

\section{Authors' contributions}

XZ and QW designed the study. YX, WP and DH performed the experiments. FF, ZW and CG performed data analysis. YX and XZ confirm the authenticity of all the raw data. All 
authors read and approved the final manuscript.

\section{Ethics approval and consent to participate}

The present study was approved by the Ethics Commission for Animal Tests of the Nanjing University of Chinese Medicine (approval no. 012009012015; Nanjing, China).

\section{Patient consent for publication}

Not applicable.

\section{Competing interests}

The authors declare that they have no competing interests.

\section{References}

1. Martinez FJ, Collard HR, Pardo A, Raghu G, Richeldi L, Selman M, Swigris JJ, Taniguchi $\mathrm{H}$ and Wells AU: Idiopathic pulmonary fibrosis. Nat Rev Dis Primers 3: 17074, 2017.

2. Lederer DJ and Martinez FJ: Idiopathic pulmonary fibrosis. N Engl J Med 378: 1811-1823, 2018.

3. Burgstaller G, Oehrle B, Gerckens M, White ES, Schiller HB and Eickelberg O: The instructive extracellular matrix of the lung: Basic composition and alterations in chronic lung disease. Eur Respir J 50: $1601805,2017$.

4. Wynn TA: Integrating mechanisms of pulmonary fibrosis. J Exp Med 208: 1339-1350, 2011.

5. Hutchinson J, Fogarty A, Hubbard R and McKeever T: Global incidence and mortality of idiopathic pulmonary fibrosis: A systematic review. Eur Respir J 46: 795-806, 2015.

6. Chanda D, Otoupalova E, Smith SR, Volckaert T, De Langhe SP and Thannickal VJ: Developmental pathways in the pathogenesis of lung fibrosis. Mol Aspects Med 65: 56-69, 2019.

7. Canestaro WJ, Forrester SH, Raghu G, Ho L and Devine BE: Drug treatment of idiopathic pulmonary fibrosis: Systematic review and network meta-analysis. Chest 149: 756-766, 2016.

8. Drakopanagiotakis F, Wujak L, Wygrecka M and Markart P: Biomarkers in idiopathic pulmonary fibrosis. Matrix Biol 68-69: 404-421, 2018.

9. da Silva Antunes R, Mehta AK, Madge L, Tocker J and Croft M: TNFSF14 (LIGHT) exhibits inflammatory activities in lung fibroblasts complementary to IL-13 and TGF- $\beta$. Front Immunol 9: 576 2018.

10. Heukels P, Moor CC, von der Thüsen JH, Wijsenbeek MS and Kool M: Inflammation and immunity in IPF pathogenesis and treatment. Respir Med 147: 79-91, 2019.

11. Zhang J, Wang D, Wang L, Wang S, Roden AC, Zhao H, Li X, Prakash YS, Matteson EL, Tschumperlin DJ and Vassallo R: Profibrotic effect of IL-17A and elevated IL-17RA in idiopathic pulmonary fibrosis and rheumatoid arthritis-associated lung disease support a direct role for IL-17A/IL-17RA in human fibrotic interstitial lung disease. Am J Physiol Lung Cell Mol Physiol 316: L487-L497, 2019.

12. Penke LR and Peters-Golden M: Molecular determinants of mesenchymal cell activation in fibroproliferative diseases. Cell Mol Life Sci 76: 4179-4201, 2019.

13. Ballester B, Milara $\mathrm{J}$ and Cortijo $\mathrm{J}$ : Idiopathic pulmonary fibrosis and lung cancer: Mechanisms and molecular targets. Int J Mol Sci 20: 593, 2019 .

14. Rogliani P, Calzetta L, Cavalli F, Matera MG and Cazzola M: Pirfenidone, nintedanib and N-acetylcysteine for the treatment of idiopathic pulmonary fibrosis: A systematic review and meta-analysis. Pulm Pharmacol Ther 40: 95-103, 2016.

15. Galli JA, Pandya A, Vega-Olivo M, Dass C, Zhao H and Criner GJ: Pirfenidone and nintedanib for pulmonary fibrosis in clinical practice: Tolerability and adverse drug reactions. Respirology 22: 1171-1178, 2017.

16. Oldham JM, Ma SF, Martinez FJ, Anstrom KJ, Raghu G, Schwartz DA, Valenzi E, Witt L, Lee C, Vij R, et al: TOLLIP, MUC5B, and the response to N-Acetylcysteine among individuals with idiopathic pulmonary fibrosis. Am J Respir Crit Care Med 192: 1475-1482, 2015.
17. Li LC and Kan LD: Traditional Chinese medicine for pulmonary fibrosis therapy: Progress and future prospects. J Ethnopharmacol 198: 45-63, 2017.

18. Feng F, Wang Z, Li R, Wu Q, Gu C, Xu Y, Peng W, Han D, Zhou X, Wu J and He H: Citrus alkaline extracts prevent fibroblast senescence to ameliorate pulmonary fibrosis via activation of COX-2. Biomed Pharmacother 112: 108669, 2019.

19. Yu Y, Sun Z, Shi L, Zhang Y, Zhou Z, Zhang S and Chao E: Effects of Feiwei granules in the treatment of idiopathic pulmonary fibrosis: A randomized and placebo-controlled trial. J Tradit Chin Med 36: 427-433, 2016.

20. Chen MJ, Yang GL, Ding YX and Tong ZQ: Efficacy of TCM therapy of tonifying lung-kidney's Qi-deficiency in a case of idiopathic pulmonary fibrosis: A case report. Medicine (Baltimore) 98: e15140, 2019.

21. Chen F, Wang PL, Fan XS, Yu JH, Zhu Y and Zhu ZH: Effect of Renshen Pingfei Decoction, a traditional Chinese prescription, on IPF induced by Bleomycin in rats and regulation of

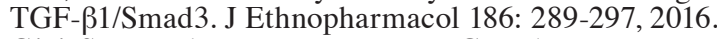

22. Giri SN, Hyde DM, Braun RK, Gaarde W, Harper JR and Pierschbacher MD: Antifibrotic effect of decorin in a bleomycin hamster model of lung fibrosis. Biochem Pharmacol 54: 1205-1216, 1997.

23. Laferriere CA and Pang DS: Review of intraperitoneal injection of sodium pentobarbital as a method of Euthanasia in laboratory Rodents. J Am Assoc Lab Anim Sci 59: 254-263, 2020.

24. Wang Z, Feng F, Wu Q, Gu C, Xu Y and Zhou X: Comparison of three methods to establish a mouse model of pulmonary fibrosis induced by intratracheal instillation of bleomycin. Chinese Journal of Comparative Medicine 29: 51-57, 2019 (In Chinese).

25. Hotham WE and Henson FMD: The use of large animals to facilitate the process of MSC going from laboratory to patient-'bench to bedside'. Cell Biol Toxicol 36: 103-114, 2020.

26. Szapiel SV, Elson NA, Fulmer JD, Hunninghake GW and Crystal RG: Bleomycin-induced interstitial pulmonary disease in the nude, athymic mouse. Am Rev Respir Dis 120: 893-899, 1979.

27. Hübner RH, Gitter W, El Mokhtari NE, Mathiak M, Both M, Bolte H, Freitag-Wolf S and Bewig B: Standardized quantification of pulmonary fibrosis in histological samples. Biotechniques 44: 507-511, 514-517, 2008.

28. Livak KJ and Schmittgen TD: Analysis of relative gene expression data using real-time quantitative PCR and the 2(-Delta Delta C(T)) method. Methods 25: 402-408, 2001.

29. Surolia R, Li FJ, Wang Z, Li H, Dsouza K, Thomas V, Mirov S, Pérez-Sala D, Athar M, Thannickal VJ and Antony VB: Vimentin intermediate filament assembly regulates fibroblast invasion in fibrogenic lung injury. JCI Insight 4: e123253, 2019.

30. Zhou Y, Tong X, Ren S, Wang X, Chen J, Mu Y, Sun M, Chen G, Zhang $\mathrm{H}$ and Liu P: Synergistic anti-liver fibrosis actions of total astragalus saponins and glycyrrhizic acid via TGF- $\beta 1 /$ Smads signaling pathway modulation. J Ethnopharmacol 190: 83-90, 2016.

31. Li Q, Hu L, Zhao Z, Ma L, Li J, Xu L and Wang J: Serum changes in pyridinoline, type II collagen cleavage neoepitope and osteocalcin in early stage male brucellosis patients. Sci Rep 10: 17190, 2020.

32. Sun YB, Qu X, Caruana G and Li J: The origin of renal fibroblasts/myofibroblasts and the signals that trigger fibrosis. Differentiation 92: 102-107, 2016.

33. Zheng X, Qi C, Zhang S, Fang Y and Ning W: TGF- $\beta 1$ induces Fstl1 via the Smad3-c-Jun pathway in lung fibroblasts. Am J Physiol Lung Cell Mol Physiol 313: L240-L251, 2017.

34. Epstein Shochet G, Brook E, Israeli-Shani L, Edelstein E and Shitrit D: Fibroblast paracrine TNF- $\alpha$ signaling elevates integrin A5 expression in idiopathic pulmonary fibrosis (IPF). Respir Res 18: 122, 2017.

35. Epstein Shochet G, Brook E, Bardenstein-Wald B and Shitrit D: TGF- $\beta$ pathway activation by idiopathic pulmonary fibrosis (IPF) fibroblast derived soluble factors is mediated by IL-6 trans-signaling. Respir Res 21: 56, 2020.

36. Gao Y, Yao LF, Zhao Y, Wei LM, Guo P, Yu M, Cao B, Li T, Chen $\mathrm{H}$ and Zou ZM: The Chinese herbal medicine formula mKG suppresses pulmonary fibrosis of mice induced by bleomycin. Int J Mol Sci 17: 238, 2016.

37. Malaviya R, Laskin JD and Laskin DL: Anti-TNFalpha therapy in inflammatory lung diseases. Pharmacol Ther 180: 90-98, 2017. 
38. Yang D, Chen X, Wang J, Lou Q, Lou Y, Li L, Wang H, Chen J, Wu M, Song X and Qian Y: Dysregulated lung commensal bacteria drive interleukin-17B production to promote pulmonary fibrosis through their outer membrane vesicles. Immunity 50 : 692-706.e7, 2019.

39. Papiris SA, Tomos IP, Karakatsani A, Spathis A, Korbila I, Analitis A, Kolilekas L, Kagouridis K, Loukides S, Karakitsos P and Manali ED: High levels of IL-6 and IL-8 characterize early-on idiopathic pulmonary fibrosis acute exacerbations. Cytokine 102: 168-172, 2018.

40. Barratt SL, Creamer A, Hayton C and Chaudhuri N: Idiopathic pulmonary fibrosis (IPF): An overview. J Clin Med 7: 201, 2018.

41. Sharif R: Overview of idiopathic pulmonary fibrosis (IPF) and evidence-based guidelines. Am J Manag Care 23 (Suppl 11) S176-S182, 2017.

42. Saito S, Alkhatib A, Kolls JK, Kondoh Y and Lasky JA: Pharmacotherapy and adjunctive treatment for idiopathic pulmonary fibrosis (IPF). J Thorac Dis 11 (Suppl 14): S1740-S1754, 2019.

43. Herrera J, Forster C, Pengo T, Montero A, Swift J, Schwartz MA, Henke CA and Bitterman PB: Registration of the extracellular matrix components constituting the fibroblastic focus in idiopathic pulmonary fibrosis. JCI Insight 4: e125185, 2019.

44. Shigemura Y, Iwasaki Y, Tateno M, Suzuki A, Kurokawa M, Sato Y and Sato K: A pilot study for the detection of cyclic prolyl-hydroxyproline (Pro-Hyp) in human blood after ingestion of collagen hydrolysate. Nutrients 10: 1356, 2018.

45. Zhu Y, Zheng X, Wang C, Sun X, Sun H, Ma T, Li Y, Liu K, Chen L and Ma X: Synthesis and biological activity of thieno[3,2-d]pyrimidines as potent JAK3 inhibitors for the treatment of idiopathic pulmonary fibrosis. Bioorg Med Chem 28 $115254,2020$.

46. Sgalla G, Iovene B, Calvello M, Ori M, Varone F and Richeldi L: Idiopathic pulmonary fibrosis: Pathogenesis and management Respir Res 19: 32, 2018.

47. Beringer A and Miossec P: IL-17 and TNF- $\alpha$ co-operation contributes to the proinflammatory response of hepatic stellate cells. Clin Exp Immunol 198: 111-120, 2019.

48. Lin J, Shi Y, Men Y, Wang X, Ye J and Zhang C: Mechanical roles in formation of oriented collagen fibers. Tissue Eng Part B Rev 26: 116-128, 2020.

49. Oike T, Kanagawa H, Sato Y, Kobayashi T, Nakatsukasa H, Miyamoto K, Nakamura S, Kaneko Y, Kobayashi S, Harato K, et al: IL-6, IL-17 and Stat3 are required for auto-inflammatory syndrome development in mouse. Sci Rep 8: 15783, 2018

50. Lei L, Zhao C, Qin F, He ZY, Wang X and Zhong XN: Th17 cells and IL-17 promote the skin and lung inflammation and fibrosis process in a bleomycin-induced murine model of systemic sclerosis. Clin Exp Rheumatol 34 (Suppl 100): S14-S22, 2016.
51. Wang YY, Jiang H, Pan J, Huang XR, Wang YC, Huang HF, To KF, Nikolic-Paterson DJ, Lan $\mathrm{HY}$ and Chen JH: Macrophage-to-myofibroblast transition contributes to interstitial fibrosis in chronic renal allograft injury. J Am Soc Nephrol 28: 2053-2067, 2017

52. Zhao W, Wang X, Sun KH and Zhou L: $\alpha$-smooth muscle actin is not a marker of fibrogenic cell activity in skeletal muscle fibrosis. PLoS One 13: e0191031, 2018.

53. Ding D, Li C, Zhao T, Li D, Yang L and Zhang B: LncRNA H19/miR-29b-3p/PGRN axis promoted epithelial-mesenchymal transition of colorectal cancer cells by acting on wnt signaling. Mol Cells 41: 423-435, 2018.

54. Schett G, Manger B, Simon D and Caporali R: COVID-19 revisiting inflammatory pathways of arthritis. Nat Rev Rheumatol 16: 465-470, 2020.

55. Saha P and Smith A: TNF- $\alpha$ (Tumor Necrosis Factor- $\alpha$ ). Arterioscler Thromb Vasc Biol 38: 2542-2543, 2018.

56. Rose-John S: Interleukin-6 family cytokines. Cold Spring Harb Perspect Biol 10: a028415, 2018.

57. Cipolla E, Fisher AJ, Gu H, Mickler EA, Agarwal M, Wilke CA, Kim KK, Moore BB and Vittal R: IL-17A deficiency mitigates bleomycin-induced complement activation during lung fibrosis. FASEB J 31: 5543-5556, 2017.

58. Zhou Z, Kandhare AD, Kandhare AA and Bodhankar SL: Hesperidin ameliorates bleomycin-induced experimental pulmonary fibrosis via inhibition of TGF-beta1/Smad3/AMPK and IkappaBalpha/NF-kappaB pathways. EXCLI J 18: 723-745, 2019.

59. Guo J, Fang Y, Jiang F, Li L, Zhou H, Xu X and Ning W: Neohesperidin inhibits TGF- $\beta 1 / \mathrm{Smad} 3$ signaling and alleviates bleomycin-induced pulmonary fibrosis in mice. Eur J Pharmacol 864: 172712, 2019.

60. Geng XQ, Ma A, He JZ, Wang L, Jia YL, Shao GY,Li M, Zhou H, Lin SQ, Ran JH and Yang BX: Ganoderic acid hinders renal fibrosis via suppressing the TGF- $\beta /$ Smad and MAPK signaling pathways. Acta Pharmacol Sin 41: 670-677, 2020.

61. Kurundkar AR, Kurundkar D, Rangarajan S, Locy ML, Zhou Y, Liu RM, Zmijewski J and Thannickal VJ: The matricellular protein $\mathrm{CCN} 1$ enhances TGF- $\beta 1 / \mathrm{SMAD} 3$-dependent profibrotic signaling in fibroblasts and contributes to fibrogenic responses to lung injury. FASEB J 30: 2135-2150, 2016.

62. Shimbori C, Bellaye PS, Xia J, Gauldie J, Ask K, Ramos C, Becerril C, Pardo A, Selman M and Kolb M: Fibroblast growth factor-1 attenuates TGF- $\beta 1$-induced lung fibrosis. J Pathol 240: 197-210, 2016. International (CC BY-NC-ND 4.0) License. 